concluded the proceedings of as good and pleasant a meeting as has ever been held.

The attendance was well over a hundred, a matter for congratulation as there were practically no members from abroad, owing no doubt to the fact that the International Congress of Ophthalmology will take place at Amsterdam next year.

\title{
BRITISH MEDICAL ASSOCIATION XCVI ANNUAL MEETING, CARDIFF, I928 Section of Ophthalmology, July 25 and 26
}

The President, Mr. F. P. S. Cresswell (Cardiff), welcomed the members and called upon Dr. Freeland Fergus (Rothesay) to open the discussion on "Visual Efficiency and Working Ability."

Dr. Fergus advanced the argument that too much is made nowadays of macular vision or visual acuteness. He entered a plea that much useful manual work can be done by persons who have quite poor macular vision. Uncorrected myopes had little central visual acuity beyond their far point, and he had given details of colliers with high amounts of myopia, who had noo difficulty in making as much money as the best-sighted collie could, and what is true of coal-mining is true of almost every otheco form of manual work. In the peripheral location of objects the? sense of projection and the subconscious estimation of distance play an important part. In the former of these the light sense and the colour intensity must be a necessity. In the latter binocular vision and convergence are important, but in the one-eyed individual other factors are of great assistance, namely, the size of the retinal image, the amount of accommodation necessary for fixation, parallax, the size of known objects, etc. The interpretation of retinal images is not a physical process, it is mental. $W$ ith regard to amblyopia in one eye, the speaker cited a medical practitioner who had no difficulty in driving his motor car, and in carrying on his practice, in spite of this defect. The speaker believed that eyes amblyopic from old convergence had no power of assisting true binocular vision.

Many men who have sufficient sight for their work are thrown out of employment because someone has discovered a trivial defect which has not interfered with the working capacity, but which has caused the insurance companies to refuse the added risk. To some extent the dole is the necessary corollary of the Workmen : Compensation Act. The speaker cited many cases of men doing useful work with very defective sight, and of others who had lost 
their employment on account of the detection of an error of refraction.

Sir J. Herbert Parsons (I,ondon) said that Dr. Fergus had dealt with a relatively small and restricted example of a general principle which was of much wider significance than even he appeared to appreciate. It was a principle which he had tried to elaborate at some length in his book on the Theory of Perception. Every stimulus, tactile, visual or auditory, modifies the complex perceptual pattern upon which it falls, and such a pattern is an integration of all the responses to all the stimuli which the animal is experiencing. Such is not a mere mathematical summation but a psychological integration sui generis. One must, therefore, not agree that the signs of visual acuity, $6 / 6,6 / 12$, and so on, should be treated as respectable members of the family of fractions, they are not always true to breeding. As a result of a resolution passed by that section at the Portsmouth meeting, the Physiology of Vision Committee of the Medical Research Council had been formed and had carried through a large amount of research work on visual problems.

Mr. N. Bishop Harman referred to the difficulties of the employer in present-day life, who wanted a minimum risk of accident to his employees, and the difficulties of the ophthalmic surgeon who had to do his duty to the employer and the workman in evolving tests of vision. The tests must be made simple of application for the general doctor, easily intelligible by the average man, and yet sufficiently comprehensive to include binocular vision, light and colour sense, accommodation and convergence.

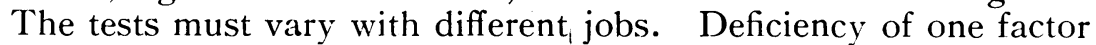
must impair the total capacity : all are essential, but their relative importance varies, and all help each other. Fields of vision are needed for work, visual acuity for good work. In school work loss of binocular vision is of little import, but defect of visual acuity for distance or near vision is serious, as it may cause, or be associated with mental dullness or failure of attainment.

Air Vice-Marshal David Munro said that after the war a number of officers in the Air Services were examined for permanent commissions. These were men picked out for the services they had rendered in the war, and it was a remarkable fact that out of 178 officers examined 177 had high visual acuity and also good binocular vision. In other words, in the process of self selection the men with lower standards of visual efficiency had dropped out. He thought that for the purpose of flying an aeroplane a high degree of acuity was not necessary, provided that fields of vision were good and that the retinal pictures were correctly superimposed and interpreted bv the brain.

Mr. H. CAIger (Sheffield) was struck with the rapidity with 
which men accommodated themselves to monocular vision after the loss of one eye. He knew miners who were earning good wages at the coal face, though they had only $3 / 60$ vision.

Mr. Spencer (Baghdad) also gave instances of one-eyed individuals, who had been good motor-drivers, pilots of aircraft, and cricketers, before and after the loss of the eye.

Mr. Robson (Penarth) had examined several thousand men, and among them were many one-eyed colliers who earned as good wages as the two-eyed men.

Dr. MACKAY (Hull) thought it would be useful to have lists of work which one-eyed men were known to be doing.

Mr. Coulter (Newport) and the President both knew of completely blind men, who were led to the coal face, and earned good wages by hewing coal.

Mr. Tudor Thomas (Cardiff) reported that he had noticed in cases of miners' nystagmus that the oscillations were most marked in the eye with the lesser acuity of vision.

Dr. FERGUS replied.

Mr. T. H. WhitTington read a paper on "The examination of the eyes and eyesight of young children." He appealed especially for the examination of children below the school age, and for the examination of children of all classes, not only those attending the school clinics, as was often the case. He suggested certain details of examination in young children, and stated that he preferred test pictures for children of three or four years as a test of visual acuity. He gave standards of vision which might be considered as sufficient at different ages, and gave notes of 4,186 children examined at Queen Mary's Hospital, Carshalton. As a routine, in cases where atropine was necessary, he preferred the use of cocaine and atropine tabloids to ointment. Where symptoms suggestive of eye-strain were present, the possibility of a cure by medical means must always be remembered, in preference to the correction of small errors of refraction.

Mr. Frank Juler (London) reported a case of bilateral obstruction in the central arteries of the retina, and recorded some observations in unilateral cases which had come under his care.

Mr. R. J. Coulter (Newport) presented some records of his observations on the light sense (as measured by Percival's discs) in 100 cases of miners' nystagmus. His main conclusions were that the light difference and the light minimum were reduced in 41 per cent. of the cases.

Mr. H. Caiger (Vice-President) was in the chair at the session on July 26, and called on Mr. W. S. Duke-Elder (London) to open the discussion on "The Aetiology of Glaucoma."

Mr. DukE-Elder outlined the arguments which made him support the theory that the aqueous humour is formed by a process 
of dialysis from the blood plasma, in a way comparable to that taken in the formation of other tissue fluids. He had found by experiment that the aqueous in all conditions is in complete thermo-dynamical equilibrium with the plasma-chemically osmotically, electrically and hydrostatically. With regard to the intra-ocular circulation three factors came into play, firstly an oscillatory flow between the blood and the aqueous depending on the fluctuations of the balancing hydrostatic and osmotic pressures on each side of the capillary walls, secondly, the thermal convection currents in the anterior chamber, and thirdly, a through-and-through pressure circulation from pressure on the outside of the globe by extra-ocular muscles, etc., which caused the aqueous pressure to exceed the venous pressure and the excess to be equalised by escape of aqueous through the canal of Schlemm (a safety valve mechanism.) He next considered how on this theory increase of the intra-ocular pressure might be caused, and classified possible methods as follows :-(1) By altering the equilibrium level: $(a)$ by raising the blood pressure in the capillaries; (b) by varying the difference between the osmotic pressure of the plasma and the aqueous. (2) Since the sclerotic is practically nondistensible the pressure may also be raised by increasing the volume of the contents of the eye. The only common condition wherein this can occur is when the volume of the vitreous and lens are increased by physico-chemical influences involving changes in turgidity pressure. He dealt with these in some detail and showed how they would explain different types of glaucoma, when the overflow mechanism was interfered with by peripheral synechiae, sclerosis of the pectinate ligament, etc. He concluded, "Taking glaucoma as a pressure symptom merely, I would suggest that the two main factors in its aetiology are these : first, a derangement of the capillary circulation, involving a capillary dilatation which produces a rise in capillary pressure or an increased permeability of the walls, allowing an excess of colloids in the fluids of the eye; secondly, changes of a physico-chemical nature in the vitreous. About the first we know little, but are rapidly learning more; about the second we know less, but are slowly finding out more. . . . Their effect depends directly on the efficiency of the drainage channels in the region of the angle of the iris."

Mr. Thomson Henderson (Nottingham) said that he was unable to accept the theory put forward by the opener of the discussion. 'The eye, like the cranium, is a closed unyielding capsule with a total fixed volume. In such a system, the intra-ocular fluid contents lie and vary with the pressure in the exit veins, because this pressure is the lowest circulatory pressure within closed spheres of eye and brain. With the ophthalmoscope, it can be seen how the slightest pressure on the globe causes constriction at the 
exit of the retinal veins. If the cerebro-spinal fluid and the aqueous were formed by dialysis, the dialysing membrane being the walls of the capillaries, there would be no necessity for such special and highly vascular structures as the choroid plexus and the ciliary processes. The great variations in the severity of the clinical manifestations of glaucoma point to the existence of two primary influences in its production. The first is a constant and predisposing factor, a pathological excess of the physiological sclerosis of the cribriform ligament, whereby the contact of aqueous with Schlemm's canal is diminished. The second factor is variable, exacting and vascular in origin : as the contact of aqueous with veins is reduced, the intra-ocular fluids act as a rigid volume, which operating through the tissues, converts the intra-ocular circulation from an elastic to a rigid system of tubes, in which the venous pressure is raised,and with it pari passu the intra-ocular.

Mr. Bishop HaRman (London) said that the eye was the scene. of a fight between the anatomists and the physiologists. The possibility of medical treatment for glaucoma was attractive, but the fear of delay and non-success drew him to surgery. There was no doubt of the various anatomical defects in the glaucomatous eye, and of the usual success of measures devised to help the excretory channels. In the present state of our knowledge, his clinical experience led him to stress the anatomical factors as of the first importance in the disease.

Mr. A. W. Ormond (London) had found the new conception of the causes of glaucoma useful in his own comprehension of the disease. Dale, by his intravenous injection of the chemical toxin, histamine, had produced rise of tension, and possibly also it might be produced by a bacterial toxin. All the signs of inflammatory glaucoma might be explained by a capillary dilatation, but he believed that there were many types of glaucoma, each with a varying cause. He expressed some doubt as to whether the more chronic types were due to alterations in the intra-ocular capillary pressure. He was sure that Priestley Smith's predisposing causes still held.

Dr. R. H. Paramore (Rugby) threw doubt on the dialysis theory. If the hydrostatic pressure within the capillaries was greater than that of the tissue fluids outside those capillaries, the latter would dilate until equilibrium was obtained, or they woul. burst. He doubted if the reputed difference in respect of permeability of capillary walls in different parts of the body, as shown for instance by variations in the composition of $1 \mathrm{ymph}$, was not due rather to a difference in the nature of the related tissue cells than to specific differences in the walls of the capillaries. With regard to histamine, it was essentially a tissue cell poison, and he thought that the results were to be explained by its effect on the 
tissue cells rather than on the capillaries. From what Mr. DukeElder had said with regard to the vitreous, it appeared to him that the swelling of that gel was a more likely cause of the increased tension. Neither a dilatation nor an increased permeability of the capillaries seemed necessary.

Lieut.-Col. A. E. J. LisTER (Bristol) said that anatomical factors must play a part, for microphthalmic eyes were liable to the disease; and he had seen it in a young patient with a small coloboma of the iris. He also cited a case where the attacks were definitely brought on by sewing for a few hours, the tension being quite normal as measured by the tonometer in the intervals. This suggested a convergence factor, with pressure from the exterior. In reply to a suggestion by Dr. SpENCER (Baghdad), he had not seen in India any suggestion of a connecticn between trachoma and glaucoma.

Messrs. Cyril Walker (Bristol), Harty (New Zealand), Quick (Swansea), and Primrose (Glasgow) also spoke, and Mr. DukeELDER replied.

Mr. A. H. Levy (London) read a paper on "Telescopic Spectacles."

Mr. Bishop HaRman demonstrated an instrument (made by Weiss) designed to assist in the mapping out of central scotoma of the visual field.

\section{ABSTRACTS}

\section{I.-MISCELLANEOUS}

(1) Finoff, William C. (Denver, Colorado). - Dry sterilization for eye instruments. Amer. Jl. of Ophthal., August, 1927.

(1) Finoff was led to use this method by the work of Morax, who had found it the most satisfactory way of sterilizing ophthalmic instruments. The knives remain polished, the points being uninjured and the edges sharp. The method is as follows : Knives are fixed in holders and placed in corked test tubes. Other instruments are arranged in metal boxes with tight fitting covers. Each container is wrapped in two layers of paper, labelled and placed in an electric sterilizer which keeps the temperature at $320^{\circ} \mathrm{F}$. for a period of half an hour. At the time of operation the paper is removed and the sterile containers handed to the surgeon, who can open them as he desires. Once sterilized the instruments can be kept indefinitely and the only objection to the method is the necessity of having more than one set of instruments, if a second operation of a similar character is done the same day.

F. A. Williamson-Noble. 